\title{
Study on the Sustainable Development Legal Mechanism of the Development and Utilization of International Watersheds
}

\author{
Han Ya $\min ^{1}$, a \\ ${ }^{1}$ Wuhan University of Technology, Luonan Street, Hongshan District, Wuhan, China \\ ahanyaminn@163.com

\begin{abstract}
The contradiction between the current situation of water shortage in the world and the increasing demand for water resources in the economic development of various countries has promoted the use of water resources in the international community to implement the concept of sustainable development. As the highest utilization rate of cross-border freshwater resources in international river basins, their cooperative development directly affects the comprehensive interests of all countries in the economic, social, and environmental aspects. This article attempts to sort out the legal basis of the concept of sustainable development in existing international rules and cases, and analyze how each subject can better implement the principles of sustainable development in the cooperative development of international river basins-perfect the integrated management model to better Promote development and protection to form a more harmonious dialectical unity relationship in practice.
\end{abstract}

Keywords: law, international river basin, sustainable development, integrated management model

\section{国际流域开发利用的可持续发展法律机制研究}

\author{
韩雅敏 ${ }^{1}$, a
}

${ }^{1}$ 武汉理工大学, 珞南街道, 洪山区, 武汉, 中国

ahanyaminn@163.com

\section{摘要}

世界范围内水资源短缺的现状与各国经济发展对水资源需求增强之间的矛盾，推动国际社会各方面对水资源 的利用都更加落实于贯彻可持续发展的理念。国际流域作为跨境淡水资源中利用率最高的一种, 其合作开发直 接影响到各国的经济、社会、环境等各方面综合利益。本文试图通过梳理可持续发展理念在现有国际规则、案 例中法律基础的体现，分析各主体在国际流域合作开发中如何更好地贯彻可持续发展原则一一完善综合管理 模式, 以更好地促进发展与保护在实践中形成更加和谐的辩证统一关系。

关键词：法律，国际流域，可持续发展，综合管理模式

\section{1.前言}

可持续发展概念由世界环境与发展委员会于 1987 年发表的《我们共同的未来》的研究报告在国际 社会首次提出, 报告指出可持续发展是指“既满足当 代人的需要, 又不对后代人满足其需要的能力构成危 害的发展”, 具体于国际流域方面, 体现在各国对国际 流域进行合作开发时, 应更关注如何在开发水资源于 当下经济发展的同时, 不损害后代或当代其他群体享
有同样利用开发水资源的条件和能力。国际流域作为 跨界水资源，与一国专属水资源不同，针对其开发利 用涉及到不同国家的发展利益，如何在各国合作开发 的过程中体现可持续发展的原则, 在分析现有的法律 基础上, 需进一步完善国际流域开发利用的综合管理 模式, 以及明确各国际社会主体作为利益共同体在水 资源开发利用中的责任承担。 


\section{2.国际流域发展与保护的辩证统一}

20 世纪 50 年代以后, 随着世界各国扩大对国际 水道的非航行利用, 人们开始增强对水资源开展生态 保护的意识。1966 年国际法协会通过的《国际河流利 用规则》中明确提出国际流域的概念，指出国际河流 的范围不仅仅局限于地表水流, 而延伸涵盖干流和支 流的地下水系统, 表明国际社会开始更加关注水资源 方面的生态保护，强调对水资源一体化的综合管理开 发, 以可持续发展的方式利用开发水资源，协调不同 主体之间的合作关系，推动国际流域方面经济发展和 环境保护的辩证统一 ${ }^{[i]}$ 。因此, 可持续发展观念愈加 被更广泛的国际社会所认可, 尤其是在跨界水资源的 开发利用上协调二者之间的关系。

不仅如此, 作为一项创新与发展的原则, 可持续 发展的观念也开始不断被人们应用于解决实践问题 中。以 1997 年多瑙河水坝案为例, 国际法院首次在 咨询意见中引入“可持续发展”的概念。本案的焦点集 中于匈牙利与捷克斯洛伐克针对多瑙河的开发利用 上, 匈牙利的科学家和环境学家认为对两国对多瑙河 进行的开发项目长期而言会对该河的生态环境造成 影响, 但捷克斯洛伐克却认为该工程不会造成严重威 胁。国际法院在对案件本身事实进行研究分析的同时, 也指出过去人类在对大自然开发利用的同时, 通常没 有考虑对环境带来的影响, 但持续的干扰会对当代和 将来的世代造成不可挽回的风险。可持续发展的概念, 反映了经济发展与环境保护相协调的必要性, 因此卫 拉曼特雷法官在其发表的个别意见书中就指出, 应当 将可持续发展作为一项具有规范性的原则应用于实 际国际法案例中, 可持续发展原则在平衡发展和环境 保护之间的竞争具有重要的作用 $[$ [ii]。因此, 发展与环 境保护的对立统一关系开始进一步应用于国际社会 开展资源利用与保护的实践中。此外, 在 2010 年的 乌拉圭纸浆厂案中, 可持续发展原则再次成为双方关 注的焦点。在国际法实践中, 可持续发展原则更多体 现为一种理念, 而不是具有可操作性的具体原则, 国 际法院在对乌拉圭纸浆厂案的裁决中进一步体现了 可持续发展在案件中的具体适用[iii]。乌拉圭和阿根廷 都提到将 “可持续发展” 作为概念和原则互换使用。双 方观点虽不完全相同, 但都同样强调在尊重可持续发 展原则的基础上, 平衡发展与保护的关系, 体现出国 家在开发本国资源的同时, 具有考虑环境保护和提升 的义务, 避免对本国以及流域经过的其他区域的环境 造成危害。协调好经济发展和环境保护的关系, 更好 地保护后代利益。

\section{3.国际流域可持续发展的法律基础}

对于国际流域的合作开发中加强对环境的保护 是各国开展跨界水资源项目合作关注的重点, 现有的 国际法律规则其中可持续发展观念的体现, 为各主体 在实践中强调环境保护的主张奠定了坚实的法律基 础。其中, 国际水法、国际发展法、国际环境法都为
国际流域的综合开发管理提供理论依据和政策保障, 包括了普遍性国际公约和区域性或双边流域协定等 等，所体现“可持续发展”原则的规定为国际社会平衡 经济发展与环境保护关系提供更加明确的理论指引。

\section{1. 普遍性国际公约中关于“可持续发展”的 规定}

普遍国际性公约中以《跨界水道和国际湖泊的保 护和利用公约》中所体现的代际公平与《联合国国际 水道非航行使用法》公约的联合管理机制为例, 体现 了不同国际公约中对可持续发展理念的相应适用。

\subsection{1, 《跨界水道和国际湖泊的保护和利用公 约》中的“代际公平”}

1992 年《跨界水道和国际湖泊的保护和利用公约》 的序言中指出其已关注到跨界水道状况变化对欧洲 经济合作组织各成员国环境、经济等产生了短期或长 期的负面影响, 需要各成员国政府加强采取在防治、 控制和减少环境污染, 促进水资源可持续发展的措施。 这体现的实则是“可持续发展”理念中的代际公平, 即 每一代人在开发利用资源时所享有的权利里都是平 等的, 我们不仅要为下一代能够选择水资源使用的权 利, 也要保证为后代所提供资源的质量, 使其享有平 等地接触和使用前代人的遗产的权利[iv]。

\subsection{2, 《联合国国际水道非航行使用法公约》中 的“联合管理机制”}

1997 年《联合国国际水道非航行使用法公约》第 21 条中指出针对跨界水资源实行的综合管理机制其 中的“管理”的根本目标是为规划水道的可持续发展, 以促进水道的合理和最佳利用、保护和控制。从而进 一步强调在开发国际水道进行非航行利用的同时, 各 国需采取合理措施以促进对河流的可持续利用与开 发, 将对水资源的管理和保护作为发展计划的有机组 成部分, 辩证统一发展与保护的关系。

\section{2. 区域性条约中关于“可持续发展”的规定}

国家间在签订区域性或双边、多边性条约时，亦 会注重贯彻可持续发展的理念, 从而有利于延长条约 的适用期限。以确保在履行环境保护的义务下, 国家 能更好地享有正当发展经济的权利。

\subsection{1, 《关于共同赞比兹河系统环境完善管理 行动计划的协定》中的“行动计划”}

1987 年在南部非洲发展协调会议的主持下, 八个 非洲国家签署的《关于共同赞比兹河系统环境完善管 理行动计划的协定》中制定了可持续发展的行动计划 以促进环境的进一步完善, 包括环境评价、环境管理、 环境立法和支持措施四个方面。该协定通过对环境进 
行系统的管理完善, 强调了在发展经济的同时, 保护 河流整体系统可持续发展的重要性, 并通过详细的行 动计划为具体活动的开展提供规划引导。

\subsection{2, 《多瑙河保护与可持续利用的合作公约》 中的可持续利用}

多瑙河流域包括多种形式的合作机制，包括双边 合作、子流域多边合作、以及国际层次的合作等等, 其中 1994 年, 多瑙河 11 个沿岸国及欧盟签署了《多 瑙河保护与可持续利用的合作公约》, 为流域的统一 行动提供支撑平台 ${ }^{[\mathrm{v}]}$ 。该公约序言明确指出各国需加 强对多瑙河及其流域内水体, 特别是跨界水体的持久 改善和保护, 以及推动针对多瑙河水资源的可持续管 理, 体现出区域性公约中对可持续发展理念的贯彻, 在开发利用促发展的同时强调保护环境的重要性。

除以上国际公约、条约外, 现有其他国际规则中 也愈来愈多地体现可持续发展的理念。国际流域作为 跨界水资源, 对其进行的开发利用不单满足一个国家 的发展需求, 而是有可能会产生多个国家的经济发展 间的利益冲突。由于国际流域流经国家的经济发展水 平的差距, 致使其对水资源开发利用具有不同程度的 要求, 不同程度的开发对水资源生态环境产生的影响 也有所差别。因此区域性或双边性条约更多地会因为 体现不同国家间对水资源开发的要求而不同，但可持 续发展观念应不约而同地融入于条约制定的始末，以 更好地促进各国在开发跨界水资源中贯彻可持续发 展的理念。

\section{4.国际流域可持续发展法律机制的主体构成}

国际流域的开发利用的主体主要是流域所涉及 影响的国家, 但除此之外, 政府间国际组织, 以及具 有群众基础的非政府组织也对跨界水资源在开发利 用中贯彻可持续发展原则具有极其重要的作用。

\section{1. 国家: 实施综合管理模式}

作为利益共同体，跨界水资源所涉及的沿岸国家 对于相应国际流域享有共同的利益, 进而承担有区别 的责任。国际流域所具备的系统性、整体性特征决定 了各个国家以可持续发展的视角开发利用水资源时, 应采取合作开发的综合管理模式, 即重视流域内整体 水平的提高, 强调各流域国间的合作与对资源的综合 利用, 进而多层次地开发流域, 形成内外协调的相互 关系 ${ }^{[\mathrm{vi}]}$ 。以《欧经委水公约》为例, 采用了集水区的 概念。将于跨境水资源相关的要素结合起来, 并应用 统一的水资源综合管理模式以加强区域、国家和地方 间的合作，从而确保水资源的有效管理和合理利用 [vii]。 流域国家采取综合管理模式开发国际流域有利于更 好地协调各方之间的利益差距, 从而推动整体流域的 可持续开发, 对生态环境系统进行整体保护。即通过 签订多边的区域性专项水协定来约定具体的综合管
理模式来更加针对性地开发利用水资源，防治具体国 际河流的水资源污染, 保护国际河流流域的生态环境 [viii]。

\section{2. 政府间国际组织：协助、促进国际流域的 可持续开发}

在对国际流域进行开发利用, 一般而言国家是行 为的主体, 是责任的承担者, 但在国际社会, 国家并 不是单一的国际生活参与主体。在对国际流域进行开 发利用, 政府间国际组织也可以参与保护和管理跨界 水资源, 并对该方面的国际事务承担相应的组织责任, 从而推动可持续发展理念更加切实有力地应用于具 体实践中。以世界银行为例, 为不发达国家实施跨界 水资源开发利用项目提供资金方面的支持。其中印度 和巴基斯坦对于印度河的开发利用一直存在冲突，世 界银行为其提供计划和建议，并提供大量的资金支持 推动项目的可持续性发展, 协调两国间的利益矛盾, 促成二者间《印度河水条约》的签订 ${ }^{[i x]}$ 。由此可见， 对于发展中国家或是不发达国家在开发利用跨界水 资源时有可能存在资金短缺的问题，世界银行作为项 目资金的提供方，其在审核国际流域开发项目时应进 一步关注项目的可持续发展性, 并以此作为是否提供 资金支持的判断标准，以此来更好地推动各国在制定 开发国际流域水资源项目中坚持可持续发展原则。因 此，政府间国际组织作为国际社会的参与者也在国际 流域可持续性开发过程中发挥协助作用, 以促进各国 间的矛盾缓和，推动项目的可持续性建设。

\section{3. 具有群分基础的非政府组织: 监督作用}

在国家开展对国际流域进行开发利用的实践中， 具有群众基础的非政府组织也会起到非常重要的作 用, 即加强公众对于可持续发展原则的认识也有利于 监督对跨界水资源的可持续开发利用的实现。以多瑙 河水坝案为例, 匈牙利国内的民间保护团体多瑙河之 友开展的政治性反对活动促使匈牙利政府决定在完 成各种调查报告尤其是环境影响得到充分评价之前 停止多瑙河水坝匈牙利方的拉基玛洛工程, 并进一步 衡量该项工程对多瑙河生态系统所造成的损害。因此, 国家开发利用跨界水资源不仅促进经济发展，符合国 家整体利益, 而且对于生态系统的影响亦会体现在群 众的日常生活中。加强群众对于水电开发项目的对于 流域生态环境影响的监督, 从下往上地推动国家更多 地关注环境保护问题, 不单单着眼于眼前的利益需求, 而是更多地考虑在对国际流域开发中对发展与保护 的协调，从而更好地促进经济的可持续发展。

\section{5. 结论}

人类在开发利用自然资源的同时要其实考虑保 护环境的需要, 既不能以开发利用牺牲环境, 也不能 以保护环境否定开发利用 $[x]$ 。可持续发展原则平衡了 二者的关系, 进而推动国家整体的健康发展。由于国 
际流域水体的关联性与功能的多样性特征, 流域国家 在合作开发跨界水资源时需要结合不同国家的经济 利益。在气候变化的背景下, 各国对于开发利用水资 源以促进本国经济发展的需求提高, 在此基础上, 如 何推动可持续发展法律机制的进一步完善: 一是在已 有的国际公约、条约的基础上, 坚持在条约的制定和 实施中贯彻可持续发展的理念; 二是明确各国际社会 主体在开发跨界水资源时对于协调发展与保护关系 所应承担的责任, 在国际社会整体化推动建立有利于 人类和自然持续发展新型社会秩序的目标的实现。

\section{REFERENCES}

[1] Bai MH. (2013) The Evolution of International Water Law Theory and International Cooperation.J.Foreign Affairs Review (Journal of China Foreign Affairs University., 5, 30: 102-112.

[2] Zhu DJ. (2013) A review of classic cases of international environmental law: the Danube dam case.J.Environmental protection and circular economy., 3, 33: 26-29.

[3] Na L. (2013) The Significance of the Judgment in the "Uruguayan River Pulp Mill Case" in Environmental Law.J.The Law., 3: 79-86.

[4] Wang L. (1998) On the Sustainable Development Principles of International Environmental Law.J.Legal Review., 3:73-78
[5] Hu W., Chen JW., Zhang CH. (2010) Practice and Enlightenment of International Cooperation in the Danube Basin.J.Resources and Environment in the Yangtze River Basin., 7, 19: 739-745.

[6] Ja L. (2008) Regional cooperation legal mechanism for international river development.J.Northern Methodology., 5:104-110

[7] Zhang F., Kong LJ. (2016) Research on the globalization of the "Convention on the Protection and Utilization of Transboundary Waterways and International Lakes" and its impact on China.J.Wuhan University International Law Review., 2, 19: 281-299.

[8] Huang XS., Wang J. ( 2008 ) Utilization of International River Water Resources: Lack of Legislation and Remedy.J.Environmental protection., 6: 37-40.

[9] Yang ZH. (2014) Research on Legal Issues of Development and Utilization of Cross-Border Water Resources in China and India。D.Wuhan University

[10] Zhang HX., Ye FF. ( 2015 ) An International Jurisprudential Analysis of China's Development and Utilization of Transboundary Rivers-A Case Study of China-Kazakhstan Transboundary River.J. Journal of Northwest University (Philosophy and Social Sciences Edition)., 5, 45: 109-116. 